\title{
In Vitro Antagonistic Effect of Lactic Acid Bacteria Isolated from Fermented Beverage and Finfish on Pathogenic and Foodborne Pathogenic Microorganism in Ethiopia
}

\author{
Fitsum Dejene, Belayneh Regasa Dadi (D), and Dagimawie Tadesse \\ Department of Medical Microbiology, Arba Minch University, Arba Minch, Ethiopia \\ Correspondence should be addressed to Belayneh Regasa Dadi; belayjanimen@gmail.com
}

Received 10 August 2021; Revised 8 September 2021; Accepted 5 October 2021; Published 15 October 2021

Academic Editor: Elena Sorrentino

Copyright (c) 2021 Fitsum Dejene et al. This is an open access article distributed under the Creative Commons Attribution License, which permits unrestricted use, distribution, and reproduction in any medium, provided the original work is properly cited.

\begin{abstract}
Background. Lactic acid bacteria from fermented foods and fish can antagonistically inhibit the growth of foodborne pathogenic organism in fermented food and they stimulate the immune response to protect the fish from certain kinds of infections. The aim of this study was to evaluate the in vitro antagonistic activities of lactic acid bacteria isolated from fermented beverage (Borde) and finfish on foodborne pathogenic microorganisms. Methods. Laboratory-based experimental study was conducted from May 1 to Sep 1, 2020. Total sample numbers were 60 samples of fermented beverage (Borde) and 20 of finfish which were collected from different households and Chamo Lake (Arba Minch, Ethiopia). Each sample was firstly homogenized and serial dilution was prepared and spread on MRS agar plates in order to isolate pure culture. Different biochemical tests were performed to identify isolated bacteria. Then, cell-free supernatant (CFS) was prepared from MRS culture and used in an antimicrobial assay that was performed by agar diffusion method. The effects of $\mathrm{pH}$, temperature, and enzymes on antimicrobial activity were evaluated in the same test. Simultaneously, the effects of lactic acid bacteria on aflatoxin production and on the permeability of the membrane were also evaluated. Data were analyzed using one-way ANOVA and Tukey post hoc analysis was performed by SPSS 25 statistical software. Result. A total of 40 lactic acid bacteria were isolated; among them, 4 lactic acid bacteria, belonging to the genera Enterococcus, Leuconostoc, and Weisellia from fermented beverage and Pediococcus from fish, were screened for antimicrobial activity. The cell-free supernatant of those four isolates exhibited a significant $(p<0.05)$ antibacterial effect against tested pathogens and foodborne pathogenic bacteria. In addition, CFS showed antifungal and antiaflatoxigenic activities. The antimicrobial compounds synthesized by these isolates were sensitive to some proteolytic enzymes, and they were proved to be stable at high temperatures. It maintained/retained antimicrobial activity in a wide range of $\mathrm{pH} 2.0-10$. Enterococcal CFS exhibited antibacterial activity against $S$. aureus on membrane permeability, as confirmed by the increase in absorbance value between 0.075 and 0.24 at $\mathrm{OD}_{280-\mathrm{nm}}$ and between 0.68 and 1.2 at $\mathrm{OD}_{260-\mathrm{nm}}$. Conclusion. Cell-free supernatant produced by isolated lactic acid bacteria showed antimicrobial activity against a wide range of Gram-positive and Gram-negative foodborne bacteria, suggesting its potential application as a natural antimicrobial agent in tackling the rising drug resistance against foodborne pathogens.
\end{abstract}

\section{Background}

All food should be safe and free of contamination at all points on its journey from the source to the consumers. However, food contamination is a serious public health problem in every country especially in Ethiopia, resulting in foodborne diseases that affect many people every year. For instance, in the USA, acute gastroenteritis affects 250 to 350 million people annually, and an estimated $22 \%$ to $30 \%$ of these cases are thought to be foodborne diseases with the main foods implicated including meat, poultry, eggs, seafood, and dairy products [1].

According to data from the Center for Disease Control and Prevention, it has been estimated that approximately one in four Americans may experience some form of foodborne illness each year. The bacterial pathogens that account for many of these cases include Salmonella, Campylobacter jejuni, Escherichia coli 0157:H7, Listeria 
monocytogenes, Staphylococcus aureus, and Clostridium botulinum [2-4]. In addition to this, some toxigenic Aspergillus strains such as A. flavus and A. parasiticus produce aflatoxin, an important carcinogenic mycotoxin with side effects such as malformations and immune suppression. The contamination of food and feed materials with aflatoxins, which have toxic, carcinogenic, and mutagenic activities, causes serious health problems and economic losses [5-8].

Until now, approaches to seeking improved food safety have relied on the search for more efficient chemical preservatives or on the application of more drastic physical treatments (e.g., high temperatures). Nevertheless, these types of solutions have many drawbacks: the proven toxicity of many commonly used chemical preservatives (e.g., nitrites), changes in organoleptic and nutritional properties of foods, and especially recent consumer trends in purchasing and consumption, with demands/requirements for safe but minimally processed products without additives [9].

In various ecological niches, microorganisms compete with each other for survival and through evolution form unique microbial communities. In some food ecosystems, lactic acid bacteria (LAB) constitute the dominant microflora. These organisms are able to produce antimicrobial compounds against competing flora, including foodborne spoilage and pathogenic bacteria. Under unfavorable environmental conditions, many species of LAB also produce exopolysaccharides (EPSs), which protect themselves against desiccation, bacteriophage, and protozoan attack [10-12].

A number of studies have shown that microorganisms from fermented foods can reach the gastrointestinal tract, this is likely to differ across products, and their presence in the gut appears to be transient [13]. Nonetheless, these microorganisms may still have the potential to exert a physiological benefit in the gut, through competition with pathogenic bacteria and the production of immune-regulatory and neurogenic fermentation by-products. Secondly, fermentation-derived metabolites may exert health benefits. For example, lactic acid bacteria (relevant to both dairy and nondairy fermented foods) generate bioactive peptides and polyamines with potential effects on cardiovascular, immune, and metabolic health $[14,15]$.

Most LAB are considered GRAS (generally recognized as safe) by the US Food and Drug Administration [16]. LAB is generally employed because they significantly contribute to the flavor, texture, and, in many cases, the nutritional value of the food products. LAB plays a defining role in the preservation and microbial safety of fermented foods, thus promoting the microbial stability of the final products of fermentation. Protection of foods is due to the production of organic acids, carbon dioxide, ethanol, hydrogen peroxide, and diacetyl, antifungal compounds such as fatty acids or phenyllactic acid, bacteriocins, and antibiotics such as reutericyclin [17].

A variety of fermented cereal beverages are produced in different parts of Ethiopia. These consist of different varieties of Tella, fermented beverage (Borde), Shamita, Korefe, and others. Fermented beverage (Borde) and Shamita are among the most important and popular fermented beverages consumed in the southern regions of Ethiopia. Fermented beverage (Borde) is produced by fermenting maize whereas barley is the major ingredient for Shamita production [18]. They are produced by an overnight fermentation of certain cereals predominantly by LAB. They are low-alcohol products and are consumed in large amounts as meal replacements [19].

Similarly, the fish gut microbiota plays an important role in GI tract development, digestive function, mucosal tolerance, stimulating the host immune response, and protection against infections. The GI tract in fish is one of the most important interfaces with the environment exposed to potential pathogens. The presence of LAB in GI tract of finfish helps them to antagonize certain pathogenic microorganisms [20]. The antimicrobial compounds from lactobacilli may inhibit bacteria as well as currently used antibiotics and chemical preservatives or applied drastic physical treatments so they may have clinical value in treatment of resistant microbial strains. Recently, many scientists have reported the presence of Lactobacillus in Borde and fish $[16,18,19]$. Due to a rise in drug resistance to commonly used antibiotics against foodborne pathogens globally [5-8], it is better to find alternatives to tackle drug resistance. One of the mechanisms is to use natural antimicrobial agents as an alternative to antibiotics. Therefore, the aim of this study was to evaluate the in vitro antagonistic activities of lactic acid bacteria isolated from fermented beverage (Borde) and finfish, on the growth of selected foodborne pathogenic microorganisms.

\section{Methods}

2.1. Study Design, Period, and Setting. Laboratory-based experimental study was conducted at Arba Minch University in Microbiology and Parasitology Laboratory, from May to September 2020. All experiments were performed in triplicate. Fermented beverage and fish were selected as a source for isolation of lactic acid bacteria (LAB) from different households in Arba Minch town and Chamo Lake (Arba Minch, Ethiopia). Arba Minch is located in Southern Nation, Nationalities and Peoples Region (SNNPR) regional zone and the administrative center of the Gamo Zone. It is located $504 \mathrm{~km}$ away from capital city Addis Ababa at $30^{\circ} 56^{\prime} \mathrm{N}$ of the equator and $37^{\circ} 44^{\prime} \mathrm{E}$ with a surface area of 2184 hectares with an average temperature of $30.6^{\circ} \mathrm{C}$ and annual rainfall of $575 \mathrm{~mm}$ [21]. Inclusion criteria include fermented food which was fresh and free from any contamination, fish that was found in adult stage, and fresh adult fish. Exclusion criteria include spoiled fermented food selected based on their texture and flavor which favors the growth of contamination, while larval stages of fish were not selected because they do not have enough amount of lactic acid bacteria in their gastrointestinal tract.

2.2. Sample Size Determination and Sampling Technique. The total sample number predicted to be taken in this experimental test was 60 samples of fermented beverage 
(Borde) (25 ml each) and 20 samples of finfish (at least $400 \mathrm{~g}$ each) that were randomly collected aseptically by using sterilized containers from different local households and fermented beverage (Borde) making microenterprises in Arba Minch, Ethiopia, and the finfish from Chamo Lake, Arba Minch, Ethiopia.

\subsection{Data Collection and Laboratory Processing}

2.3.1. Sample Collection. Fermented beverage and fish were selected as a source for isolation of LAB. A food product and finfish which was subjected to study were 60 fermented beverage (Borde) samples and 20 samples of fish were collected from different households and Chamo Lake (Arba Minch, Ethiopia), respectively. The samples were kept in an icebox and transported to the laboratory within 3 hours; these samples were stored at $-4^{\circ} \mathrm{C}$ until used for further analysis.

2.3.2. Bacteria Used for Experimental Study. The standard strains used in this study were Staphylococcus aureus ATCC25923, Klebsiella pneumonia ATCC700603, Pseudomonas aeruginosa ATCC27853, Escherichia coli ATCC25922, and Aspergillus flavus. The strains were obtained from the collection center of Ethiopian Public Health Institute (EPHI) except Aspergillus flavus which was isolated and identified following growth on selective DzapexDox Agar (DDA) followed by morphological and microscopic characterization. All strains used in the experimental study were destroyed after the study was completed by autoclaving at a temperature of $121^{\circ} \mathrm{C}$ for 15 minutes using saturated steam under 15 psi pressures.

2.4. Isolation and Maintenance of Pure Cultures. Ten grams of each sample was homogenized with $90 \mathrm{ml}$ of $0.85 \%$ (w/v) saline and serially diluted. One hundred microliters of the desired sample suspension was spread on MRS agar media. After plating the samples, the plates were incubated both aerobically and anaerobically at $37^{\circ} \mathrm{C}$ for $24 \mathrm{hrs}$. Colonies were selected randomly and purified by restreaking. Purified strains were stored as stock at $-4^{\circ} \mathrm{C}$ till further use.

\subsection{Phenotypic Identification and Biochemical Character-} ization of $L A B$. According to Kumar Colony morphology, cell morphology, arrangement, and Gram staining were done for phenotypic characterization. Colony shape (both elevation and margin), size, color, and consistency were observed. Other characteristics of the colonies such as smoothness (shiny glistening surface), roughness (dull, bumpy, granular, or matte surface), mucoidity (slimy or gummy appearance), and opacity (transparent, translucent, or opaque) were also noted. Gram staining was performed in order to categorize the isolates into Gram positive or Gram negative and rods, cocci, or coccobacilli. An endospore staining test was also performed to distinguish between spore and nonspore-forming bacteria. Endospores appeared bright green and vegetative cells brownish red to pink under microscope. Then, finally, the biochemical test was used to identify the isolated LAB species [22].

2.6. Preparation of Cell-Free Supernatants. Strains to be tested for antimicrobial activity were incubated in MRS broth for $48 \mathrm{~h}$ at $37^{\circ} \mathrm{C}$. Bacterial cells were removed by centrifugation of the culture at $5000 \times g$ for $20 \mathrm{~min}$ at $4^{\circ} \mathrm{C}$. The $\mathrm{pH}$ values of supernatants were adjusted to $\mathrm{pH}$ 6.5-7.0 by the addition of $1 \mathrm{~N} \mathrm{NaOH}$. The supernatants were membrane filtered (Millipore, $0.22 \mu \mathrm{m}$ ) and stored at $4^{\circ} \mathrm{C}$ until use [23].

2.7. Antimicrobial Assay. The antimicrobial activity of LAB was determined by a well-diffusion assay as described by Kojic et al. in 1991 [24]. In brief, the antimicrobial susceptibility was initially assayed by the agar well-diffusion method on the Mueller-Hinton agar (MHA). $100 \mu$ l of each CFS was prepared. The selected pathogenic and foodborne pathogenic bacteria cell suspensions were adjusted to 0.5 McFarland turbidity standards to prepare $1 \times 10^{8}$ bacteria/ $\mathrm{ml}$ inoculums. Each bacterial suspension was inoculated on Mueller-Hinton agar plates, and the plates were then allowed to dry for 5 minutes. Wells were punctured in the medium then sealed with sterile molten agar. Cell-free supernatant (100 microliters) was added to the respective wells. MRS broth was used as a negative control. CFSs were neutralized to $\mathrm{pH} 6.5$ or 7 to maintain that the inhibition was not due to lactic or other organic acids but by antimicrobial substances. After $48 \mathrm{~h}$ incubation at $37^{\circ} \mathrm{C}$ aerobically, the diameter of zones of inhibition $(\mathrm{mm})$ was measured.

2.8. Effect of pH, Temperature, and Enzyme on CFS Antimicrobial Activity. Sensitivity to enzymes was checked by treatment with proteolytic enzymes: trypsin (BIO BASIC Canada INC) and pepsin and with lysozyme (BIO BASIC Canada INC); fifty microliters of the CFS was mixed with enzymes solutions to obtain final concentration and $1 \times$ reaction buffer. Incubation was held at $37^{\circ} \mathrm{C}$ for $1 \mathrm{~h}$. After incubation, the enzymes were denatured by heating the samples at $80^{\circ} \mathrm{C}$ for $10 \mathrm{~min}$, and the residual CFS activity was determined. The effect of $\mathrm{pH}$ on the CFS antimicrobial activity was determined by adjusting the $\mathrm{pH}$ of CFS using $1 \mathrm{~N} \mathrm{HCl}, 1 \mathrm{~N} \mathrm{NaOH}$, and $\mathrm{pH}$ meter following that $\mathrm{pH} 2, \mathrm{pH}$ $4, \mathrm{pH} 6, \mathrm{pH} 10$, and $\mathrm{pH} 12$ were used. After $2 \mathrm{~h}$ of incubation at room temperature, the samples were readjusted to $\mathrm{pH} 6.5$ with sterile $1 \mathrm{~N} \mathrm{HCl}$ or $1 \mathrm{~N} \mathrm{NaOH}$, and the activity was determined. Staphylococcus aureus ATCC25923 was used as an indicator bacterium.

2.9. Effect of CFS on the Leakage of Cellular Metabolites. Bacterial culture of $S$. aureus ATCC25923 in $10 \mathrm{ml}$ of nutrient broth $(\mathrm{NB})$ at the exponential growth stage was transferred into several sterile centrifuge tubes and was centrifuged at $4,800 \times g$ for $15 \mathrm{~min}$. After the supernatant was discarded, the pellet was resuspended in $10 \mathrm{ml}$ of $\mathrm{NB}, \mathrm{pH}$ 7. The cell suspension was centrifugated twice and resuspended in $10 \mathrm{ml}$ of NB. Bacterial suspensions of the S. aureus 
ATCC25923 from all centrifuge tubes were pooled, and $\mathrm{OD}_{540}$ values and viable counts of bacteria were determined. Then $10 \mathrm{ml}$ aliquots were dispensed into each of six sterile flasks $(50 \mathrm{ml}) .1 \mathrm{ml}$ of CFSs was added to cells and control (without CFS) was prepared. At 1-, 2-, and 3-hour time intervals of treatment, cells were centrifuged at $3,500 \times g$, the suspension was filtered through $0.22 \mu \mathrm{m}$ sterile filters, and the filtrate was used for determination of nucleic acids at $\mathrm{A} 260 \mathrm{~nm}$ and proteins at A280 nm. The differences of absorption value at A260 and A280 nm between controls and test groups were used to estimate/ quantify the release of metabolites. The experiments were done in triplicate [25].

2.10. Effect of Lactic Acid Bacteria on Growth Rate and Aflatoxin Production of A. flavus. The spore suspension was prepared from pure cultures of Aspergillus flavus (21 days old) grown on the Czapexdox medium. The plates were flooded with $0.05 \%$ Tween 80 and brushed thoroughly for 12 min with a sterilized slide. The suspension was filtered through three layers of sterile cheesecloth to remove the mycelia residues. The number of spores $/ \mathrm{ml}$ was counted in the collected spore suspension by using a Neubauer-improved haemacytometer and was adjusted to $20 \times 10^{4}$ spores/ $\mathrm{ml}$ in Czapexdox Medium [26].

The effect of lactobacilli on aflatoxin production by Aspergillus flavus was tested by inoculating $2 \mathrm{~mL}$ of bacterial CFS in $50 \mathrm{ml}$ yeast extract sucrose broth (YESB) supplemented with a standard amount of fungal spores $\left(20 \times 10^{4}\right.$ spores $/ \mathrm{ml}$ ), followed by incubation at $28^{\circ} \mathrm{C}$ for 20 days. YESB media supplemented with known fungal spores and YESB media without any inoculation were incubated as positive and negative controls, respectively. After incubation, medium containing CFS and fungus was filtered through sterile Whatman filter paper no. 1, fungal mycelial mass was weighed after drying in an oven at $70^{\circ} \mathrm{C}$, and aflatoxin $\mathrm{B} 1$ quantity in filtrate was measured by Enzyme-Linked Immune Sorbent Assay (ELISA) and compared with controls [27]. Aflatoxin was detected by ELISA and quantified using the calibration curve.

$$
\text { Percentage of Absorbance }(\%)=\frac{B}{B 0} * 100 \% \text {, }
$$

where $B$ is the absorbance of standard or sample, $B 0$ is the absorbance of zero standards, and $\%$ age reduction $=1-$ ( (concentration of AFB1 in treatment)/ (concentration of AFB 1 in control)).

\subsection{AFB1 Extraction for ELISA Analysis. Aflatoxin B1 was} extracted by adding $25 \mathrm{ml}$ chloroform to each culture flask which was then shaken for 15 minutes on a rotary shaker model no. RSE056 (150-160 rpm). After phase separation by rotary evaporator S/N 200095320, the chloroform layer was removed and the extraction was repeated with additional $25 \mathrm{ml}$ chloroform. Combined extracts were dehydrated over granular anhydrous sodium sulfate and evaporated to dryness at $60^{\circ} \mathrm{C}$ in a water bath. Residues were dissolved in
$1 \mathrm{ml}$ of chloroform for analysis. Aflatoxin B1 concentration was determined by ELISA [26].

2.12. Data Quality Assurance. Data quality control was ensured from data collection up to final laboratory identification by following the prepared standard operating procedure (SOP). The performance of the prepared media was checked by inoculating control strains like Staphylococcus aureus ATCC25923 and Escherichia coli ATCC25922, which was obtained from Ethiopian Public Health Institute (EPHI). Culture media was prepared according to manufactures instruction, and the sterility was checked by incubating $5 \%$ of prepared media at $35-37^{\circ} \mathrm{C}$ overnight and observing bacterial growth. Those batches of the media that show the growth were discarded and reprepared. Data quality control for the experimental unit is Positive and Negative Control Unit.

2.13. Statistical Analysis. All experiments were performed in triplicate. Data were analyzed within one-way ANOVA and statistical analysis was performed using post hoc Tukey test by SPSS 25 (IBM Statistics, Armonk, NY) statistical software. $p \leq 0.05$ was considered as the statistical significance level.

\section{Results}

3.1. Morphological Identification. The identification was performed for four isolates, which is according to the morphological and microscopic characteristics. The macroscopic appearance of all colonies was examined for morphological characteristics. The size, shape, color, and texture of colonies were recorded. The macromorphological characteristics of different isolates studied on MRS agar plates are summarized in Table 1.

Through Gram staining and microscopy, the isolates were differentiated into Gram-positive cocci or coccobacilli. Out of 4 isolates, all were found to be Gram-positive. Out of all samples, 4 different bacteria were isolated of which micromorphologically 2 were cocci and 2 were coccobacilli (Table 2).

3.2. Biochemical Characterization. After morphological studies, various biochemical tests were performed with isolated bacteria in order to identify isolates on the basis of their biochemical characteristics. All 4 isolates were catalasenegative and nonmotile and all were fermentative. Some of the isolates could grow at $15^{\circ} \mathrm{C}$ and some of the strains were able to grow at $45^{\circ} \mathrm{C}$ (Table 3 ).

Further biochemical analysis was done through which 8 carbohydrates utilization tests were performed. By studying the results of this test, different isolates could be tentatively characterized on the basis of their biochemical nature (Table 4). According to the biochemical tests, the 4 isolates could be tentatively categorized into Enterococcus sp., Pediococcus sp., Weissella sp., and Leuconostoc sp., and Enterococcus, Leuconostoc, and Weissella were isolated from fermented beverage (Borde), while Pediococcus was isolated from finfish. 
TABle 1: Morphological characteristics of colonies of different bacterial isolates.

\begin{tabular}{llclllc}
\hline Isolates & Form & Elevation & Margin & Surface & Opacity & Chromogenesis \\
\hline Leuconostoc & Circular & Convex & Entire & Smooth & Opaque & Off white \\
Enterococcus & Circular & Flat & Entire & Smooth & Opaque & White \\
Weissella & Circular & Convex & Entire & Smooth & Opaque & Yellowish white \\
Pediococcus & Circular & Convex & Entire & Smooth & Opaque & Yellowish white \\
\hline
\end{tabular}

TABLE 2: Micromorphology of bacteria isolated from Borde and finfish.

\begin{tabular}{lcc}
\hline Isolates & Naming (arrangement) & Types of colony \\
\hline Leuconostoc & Cluster & Coccobacilli \\
Enterococcus & Diplococcic or short streptococci & Cocci \\
Weissella & Tetragenococcus & Cocci \\
Pediococcus & Cluster & Coccobacilli \\
\hline
\end{tabular}

TABLE 3: Summary of different micromorphological/biochemical tests of isolates.

\begin{tabular}{lccccccccc}
\hline Isolates & $\begin{array}{c}\text { Gram } \\
\text { staining }\end{array}$ & $\begin{array}{c}\text { Catalase } \\
\text { test }\end{array}$ & $\begin{array}{c}\text { Citrate } \\
\text { utilization test }\end{array}$ & $\begin{array}{c}\text { Hydrogen sulfide } \\
\text { production }\end{array}$ & $\begin{array}{c}\text { Motility } \\
\text { test }\end{array}$ & $\begin{array}{c}\text { Indole } \\
\text { test }\end{array}$ & $\begin{array}{c}\text { Methyl red } \\
\text { test }\end{array}$ & $\begin{array}{c}\text { Growth at } \\
15^{\circ} \mathrm{C}\end{array}$ & $\begin{array}{c}\text { Growth at } \\
45^{\circ} \mathrm{C}\end{array}$ \\
\hline Leuconostoc & + & - & - & - & Nonmotile & - & & + & + \\
Enterococcus & + & - & - & - & Nonmotile & - & + & + \\
Weissella & + & - & - & - & Nonmotile & - & + & + & + \\
Pediococcus & + & - & - & - & Nonmotile & - & + & + & + \\
\hline
\end{tabular}

TABLE 4: Summary of carbohydrate utilization test.

\begin{tabular}{|c|c|c|c|c|c|c|c|c|}
\hline Fermentation test & Lactose & Glucose & Sorbitol & Maltose & Fructose & Sucrose & Starch & Mannitol \\
\hline Leuconostoc & + & + & - & + & + & + & + & + \\
\hline Enterococcus & + & - & + & + & + & + & - & + \\
\hline Weissella & - & + & + & - & + & - & - & + \\
\hline Pediococcus & + & + & + & + & + & + & - & + \\
\hline
\end{tabular}

3.3. Antibacterial Potential of LABCFS on Pathogenic Organism. The antibacterial activity of CFS of all isolates against the tested foodborne pathogenic bacteria was confirmed by the presence or absence of inhibition zones around well on the agar plates. As presented in Table 5, CFS of some isolates exhibited potent inhibitory effects against all the tested foodborne pathogenic bacteria. In this assay, most isolates exerted consistent antibacterial effects against both Grampositive and Gram-negative bacteria, with a zone of inhibition diameters ranging from 7 to $11 \mathrm{~mm}$ for neutralized CFS, while it was 13 to $20 \mathrm{~mm}$ for nonneutralized CFS. MRS medium, used as a negative control, had no inhibitory effect (Table 5).

Generally, when inhibition zones produced by isolates belonging to each $\mathrm{LAB}$ genus were compared, there was a statistically significant difference between groups as demonstrated by one-way ANOVA $[F(4,15)=7.238, p=0.002]$. A Tukey post hoc test showed that there was no statistically significant difference between the groups, However, there is a statistically significant difference in comparison with the negative control $(p<0.05)$ except the group that is treated by Weissella and Leuconostoc. Among the test strains, the most sensitive were S. aureus ATCC25923 for Enterococcus, Pediococcus, and Weissella, while K. pneumonia ATCC700603 was more sensitive to Leuconostoc isolate. E. coli ATCC25922 was the least sensitive in all cases.
3.4. Inhibitory Activity of CFS following Heat Treatments. The CFS produced by the four selected LAB isolates were heat-treated at 60 and $100^{\circ} \mathrm{C}$ for $10 \mathrm{~min}$. The antimicrobial compound in CFSs was thermally stable under these heat conditions above as their inhibitory effects against $S$. aureus were observed (Table 6). Nevertheless, CFS lost activity after temperature treatment at $121^{\circ} \mathrm{C}$ for 10 min displaying no inhibition zones compared to the control.

3.5. Inhibitory Activity of CFS following Enzyme Treatments. The sensitivity of the CFS to trypsin, pepsin, and lysozyme was determined in controlled and reproducible conditions as shown in Table 7 . The inhibitory substance was fully inactivated by proteolytic enzymes, while the lysozyme enzyme had no effect on the antagonistic activity.

3.6. Inhibitory Activity of CFS at Different $p H$ Condition. The exposure of CFS to different $\mathrm{pH}$ values showed that all antimicrobial substances remained fully active in the $\mathrm{pH}$ range from 2-8 and also at $\mathrm{pH} 10$. Reduced activities of antimicrobial substances from CFS of all isolates were found after treatment at $\mathrm{pH} 12.0$ (Table 8). 
TABLE 5: Inhibition of various indicator organisms by CFS produced by lactic acid bacteria.

\begin{tabular}{lcccc}
\hline Isolates & E. coli ATCC25922 & S. aureus ATCC25923 & K. pneumonia ATCC700603 & P. aeruginosa ATCC27853 \\
\hline Enterococcus NCFS & $16 \mathrm{~mm}$ & $19 \mathrm{~mm}$ & $18 \mathrm{~mm}$ & $18 \mathrm{~mm}$ \\
Enterococcus NNCFS & $7 \mathrm{~mm}$ & $11 \mathrm{~mm}$ & $9 \mathrm{~mm}$ & $10 \mathrm{~mm}$ \\
Pediococcus NNCFS & $18.4 \mathrm{~mm}$ & $17 \mathrm{~mm}$ & $18 \mathrm{~mm}$ & $17 \mathrm{~mm}$ \\
Pediococcus NCFS & $8 \mathrm{~mm}$ & $12 \mathrm{~mm}$ & $11 \mathrm{~mm}$ & $10 \mathrm{~mm}$ \\
Leuconostoc NNCFS & $17 \mathrm{~mm}$ & $15 \mathrm{~mm}$ & $9 \mathrm{~mm}$ & $8 \mathrm{~mm}$ \\
Leuconostoc NCFS & $8 \mathrm{~mm}$ & $7 \mathrm{~mm}$ & $9 \mathrm{~mm}$ & ND \\
Weissella NNCFS & $15 \mathrm{~mm}$ & $17 \mathrm{~mm}$ & $\mathrm{ND}$ & $10 \mathrm{~mm}$ \\
Weissella NCFS & $8 \mathrm{~mm}$ & $9 \mathrm{~mm}$ & $\mathrm{ND}$ & $\mathrm{ND}$ \\
Negative control (MRS) broth & $\mathrm{ND}$ & $\mathrm{ND}$ & & ND \\
\hline
\end{tabular}

Note. ND: not detected; NNCFS: nonneutralized CFS; NCFS: neutralized CFS.

TABLE 6: Thermal stability of CFS produced by the selected LAB following various heat treatments (S. aureus ATCC25923 was used as an indicator bacterium).

\begin{tabular}{lccc}
\hline Isolates & $60^{\circ} \mathrm{C}, 10 \mathrm{~min}$ & $100^{\circ} \mathrm{C}, 10 \mathrm{~min}$ & $121^{\circ} \mathrm{C}, 10 \mathrm{~min}$ \\
\hline Enterococcus NCFS & ++ & + & -- \\
Pediococcus NCFS & ++ & + & -- \\
Leuconostoc NCFS & ++ & + & -- \\
Weissella NCFS & ++ & + & -- \\
MRS + enzyme & -- & -- & -- \\
\hline
\end{tabular}

Note. $++=$ inhibition zone $(7-10 \mathrm{~mm}) ;+=$ inhibition zone $(<5 \mathrm{~mm})$; $--=$ no inhibition zone.

TABLE 7: Inhibitory activity of CFS following enzyme treatments (S. aureus ATCC25923 was used as an indicator bacterium).

\begin{tabular}{lccc}
\hline Isolate & Trypsin & Pepsin & Lysozyme \\
\hline Enterococcus NCFS & - & - & ++ \\
Pediococcus NCFS & - & - & ++ \\
Leuconostoc NCFS & - & - & ++ \\
Weissella NCFS & - & - & ++ \\
MRS + enzyme & - & - & - \\
\hline
\end{tabular}

Note. $++=$ inhibition zone $(7-10 \mathrm{~mm}) ;+=$ inhibition zone $(<5 \mathrm{~mm}) ;-=$ no inhibition zone.

TABLE 8: Inhibitory activity of CFS following different $\mathrm{pH}$ treatments (S. aureus ATCC25923 was used as an indicator bacterium).

\begin{tabular}{lcccc}
\hline Isolates & $\mathrm{pH} 2$ & $\mathrm{pH} 4$ & $\mathrm{pH} 10$ & $\mathrm{pH} 12$ \\
\hline Enterococcus NCFS & ++ & ++ & ++ & + \\
Pediococcus NCFS & ++ & ++ & ++ & + \\
Leuconostoc NCFS & ++ & ++ & ++ & + \\
Weissella NCFS & ++ & ++ & ++ & + \\
MRS broth & + & + & + & + \\
\hline
\end{tabular}

Note.++=inhibition zone $(20-13 \mathrm{~mm}) ;+=$ inhibition zone $(<13 \mathrm{~mm})$.

3.7. Effect of CFS on the Release of Intracellular Component Materials. The ODs of culture filtrates of $S$. aureus ATCC25923 cells exposed to the CFS of Enterococcus at $260 \mathrm{~nm}$ and $280 \mathrm{~nm}$ revealed a significant time-dependent increase in the release of $260 \mathrm{~nm}$ and $280 \mathrm{~nm}$ absorbing materials. However, no changes in the OD of control cells of the tested pathogen were observed.
The absorption of the material cell at 260 and $280 \mathrm{~nm}$ in spectrophotometer UV from filtrated samples and control suspension were significantly different. The absorption value indicates that there is leakage of intracellular macromolecules. Molecules that absorb at $260 \mathrm{~nm}$ are nucleic acids and at $280 \mathrm{~nm}$ are proteins. Significant increases in the absorption at $260 \mathrm{~nm}$ and $280 \mathrm{~nm}$ occurred after treatment with CFS.

3.8. Antifungal Potential of LABCFS on Aspergillus flavus. All the studied LAB strains exhibited various degrees of growth inhibition against Aspergillus species. All tested LAB strains showed antifungal activity against $A$. flavus. The indicator strain A. flavus was the most sensitive to Enterococcus isolate that was followed by Pediococcus, Leuconostoc, and Weissella.

Each isolate significantly reduced the growth rate of A. flavus in comparison with the positive control as demonstrated by one-way ANOVA $(F(4,10)=113.386$, $p \leq 0.001)$. However, there was no significant difference between the antifungal activities of these four isolates (Table 9).

3.9. Antiaflatoxigenic Effect of LABCFSs on Aspergillus flavus AFB1 Production. The production of Aflatoxin B1 was greatly affected by the presence of all the investigated LAB species. Data presented in Table 10 indicate that the inhibitory effect on Aflatoxin B1 production by A. flavus ranged from $98.1 \%$ in the presence of Leuconostoc to $99.8 \%$ in the presence of Enterococcus after 15 days of incubation. Based on the differences in antifungal activity by LAB cultures and the controls, Enterococcus isolate was the most antifungal (79.7\% growth reduction) and antiaflatoxigenic (99.8\% reduction of $\mathrm{AFB}_{1}$ production) to the test strains, while Weissella was the weakest antifungal and antiaflatoxigenic isolate.

All isolates significantly reduced the production of $\mathrm{AFB}_{1}$ (Aflatoxin B1) in comparison with the positive control as demonstrated by one-way $\operatorname{ANOVA}(F(4,10)=533.307$, $p \leq 0.001)$. However, there was no significant difference between the antiaflatoxigenic activities of these four isolates (Table 10). 
TABLE 9: Mycelial mass production by A. flavus in the presence of LAB.

\begin{tabular}{lcc}
\hline Species & Mycelial mass (gm) & Percent of mycelial mass reduction (\%) \\
\hline A. flavus + Enterococcus CFS & 0.16 & 79.7 \\
A. flavus + Pediococcus CFS & 0.20 & 74.7 \\
A. flavus + Leuconostoc CFS & 0.23 & 70.9 \\
A. flavus + Weisella CFS & 0.27 & 65.8 \\
A. flavus & 0.79 & - \\
\hline
\end{tabular}

TABLE 10: Effect of LABCFS on the concentration of $\mathrm{AFB}_{1}$ produced by toxigenic A. flavus.

\begin{tabular}{lcc}
\hline Species & $\mathrm{AFB}_{1}(\mathrm{ppm})$ & $\mathrm{AFB}_{1}$ percent of reduction $(\%)$ \\
\hline A. flavus + Enterococcus CFS & 46.3 & 99.8 \\
A. flavus + Pediococcus CFS & 135 & 99.3 \\
A. flavus + Leuconostoc CFS & 403.3 & 98.1 \\
A. flavus + Weisella CFS & 252 & 98.8 \\
A. flavus & 20690 & - \\
\hline
\end{tabular}

\section{Discussion}

In our experimental study, 4 lactic acid bacteria isolated from finfish and fermented beverage (Borde) were identified based on its micromorphological, biochemical, and fermentation abilities test result. In this study, 4 isolates of LAB were screened for its antibacterial activities against the pathogenic and foodborne pathogenic organisms. As confirmed by inhibitory zones in the agar well-diffusion assay Pediococcus, Enterococcus, Leuconostoc, and Weissella were used to investigate the antagonistic activity. As reported previously, several LAB have shown potential antibacterial effects against a number of pathogenic and foodborne pathogenic organisms [28-30]. In this assay, 4 strains of pathogenic and foodborne pathogenic bacteria (S. aureus ATCC25923, E. coli ATCC25922, K. pneumonia ATCC700603, P. aeruginosa ATCC27853), and A. flavus were used to evaluate the antagonistic effects of CFS of those 4 isolates.

The antibacterial activity of the four LAB strains confined from fermented beverage (Borde) and finfish has been examined primarily in vitro, and studies have especially centered on the inhibitory activity against the growth of Gram-negative and Gram-positive pathogens. An antibacterial substance of CFS produced by Enterococcus, Pediococcus, Leuconostoc, and Weissella strains exhibited inhibitory activity against all four bacterial strains $S$. aureus, E. coli, K. pneumonia, and $P$. aeruginosa. A recent review has similarly demonstrated that isolated species of Lactobacillus exert antagonistic impact in vitro against pathogenic and foodborne pathogenic organisms by creating antibacterial metabolites, most of which remain to be recognized [31, 32]. There is expanding prove that the antibacterial action of LAB includes various mechanisms of action, including the generation of lactic acid and antimicrobial substances like bacteriocins and nonbacteriocin molecules [33-35].

The CFS antagonistic activity of isolated bacteria can be influenced by a few proteolytic enzymes driving to loss in their antagonistic action. In this study, S. aureus was utilized as an indicator organism and the CFS of LABs had diverse inhibitory impact taking after treatment with a proteolytic enzyme. A comparable character was observed by
Lactobacillus plantarum bacteria. They found that proteolytic enzymes like pepsin and trypsin treatment hindered the antagonistic activity of test strain [36]. Scatassa and his colleague also reported that the strain of Lactobacillus exhibited similar antibacterial activity, inhibiting L. monocytogenes ATCC 7644 and eight L. monocytogenes of food origin and the proteolytic enzyme treatment of cell-free supernatant of Lactobacillus eliminated all inhibitory activity, confirming that the toxins were proteinaceous in nature [37].

The antagonistic activity of CFS illustrated by the four isolates was too $\mathrm{pH}$-dependent. The foremost antagonistic activity was displayed in the acidic $\mathrm{pH}$ range of 2 to 5 , whereas loss of antagonistic was observed in alkaline $\mathrm{pH}$ condition $(\mathrm{pH}>10)$. The same result was reported by Pehrson et al. in which lactic acid bacteria, specifically L. acidophilus ATCC 4356 obtained from the research center, appeared to have the most elevated antagonistic activity and stability at $\mathrm{pH} 2$ and 4 [29].

The stability of the antagonistic compound of CFS was also analyzed at diverse temperatures. The CFS produced by the four isolates was considered as moderately stable since no reduction in activity after heating at $60^{\circ} \mathrm{C}$ and $100^{\circ} \mathrm{C}$ for $10 \mathrm{~min}$ was observed, whereas it lost its activity at above $100^{\circ} \mathrm{C}$. The same result was also reported showing loss of activity after heat treatment at $121^{\circ} \mathrm{C}$ for $15 \mathrm{~min}$ [36]. Furthermore, Nowroozi and his colleague also reported that lactic acid bacteria isolated from sausage had antibacterial activity and the antibacterial activity was stable at $100^{\circ} \mathrm{C}$ for 10 minutes and at $56^{\circ} \mathrm{C}$ for 30 minutes but actively was lost after autoclaving [38].

In this study, it was demonstrated that CFS of Enterococcus species had exceptional impacts on the discharge of $260 \mathrm{~nm}$ and $280 \mathrm{~nm}$ materials like nucleic acids (DNA; RNA) and proteins from the cells of tested S. aureus ATCC25923 bacteria, which affirmed its potential as a strong antibacterial agent. According to Bajpai et al., marked discharge of 260 $\mathrm{nm}$ and $280 \mathrm{~nm}$ materials from CFS treated cells of pathogenic bacteria was supported by the observation of loss of cell membrane structural integrity, which would lead to the loss of basic cell metabolite [39]. These results recommend that the leakage of $260 \mathrm{~nm}$ and $280 \mathrm{~nm}$ absorbing materials 
from $S$. aureus might give sensitive indicator membrane damage and loss of membrane integrity. Comparable results on the inhibitory impact of CFSs on nucleic acid and protein leakage from bacterial pathogens have been previously reported [40]. Numerous antimicrobial compounds that act on the bacterial cytoplasmic layer initiate the loss of $260 \mathrm{~nm}$ absorbing materials (nucleic acid) and proteins as $280 \mathrm{~nm}$ absorbing material [36].

In the investigation with respect to the antifungal and antiaflatoxigenic activity of LAB, Enterococcus and Pediococcus caused a basic reduction within the mycelial development of $A$. flavus. Besides, LAB had shown inhibitory impacts on the production of Aflatoxin B1 from 98.8 to $99.8 \%$ in comparison with the control. The result of this study is in agreement with the study conducted within the College of Nebraska-Lincoln, USA, in which three of LAB of L. plantarum, L. rhamnosus, and L. paracasei hindered the growth of mold and mycotoxin producing A. flavus and A. parasiticus [26]. The same study was conducted by Rafaat in which the antifungal action by lactic acid bacteria hindered both the growth and aflatoxin production of $A$. flavus $[32,41]$. Similarly, Erick and his colleague investigated that thirteen out of the 18 tested lactic acid bacteria showed antifungal activity. Almost all lactic acid bacteria supernatants tested showed antifungal activity at a certain growth phase, probably due to the acidifying of the supernatants [41]. Furthermore, Aiko and Mehta similarly reported that few strains of lactic acid bacteria showed an ability to remove aflatoxins B1 and M1 by binding noncovalently indicating that binding and not metabolism is the mechanism by which the toxins are removed [42]. The inhibition of fungal development and aflatoxin production by these bacteria likely is due to different factors such as nutrient competition, secondary metabolites, $\mathrm{pH}$, or their combinations $[34,40]$.

Overall our findings indicate that LAB can be used to inhibit the growth of pathogenic and/or potentially pathogenic microorganisms and can be used as an alternative antimicrobial agent as there is a growing concern of antibiotic resistance to drugs used for foodborne pathogens. In addition, it is safe to use LAB to preservative foods in industries rather than using a chemical preservative.

4.1. Limitations of the Study. HPLC analysis and purification of antagonistic metabolite were not performed due to the fact that the machine currently is not giving any service because of the COVID-19 pandemic. Species identification was not performed due to the lack of RAPD-PCR primer and API 50CH Lactobacillus identification KIT. Effect of CFS on cell morphology and intracellular organization was not performed due to the fact that the SEM machine was not operational during the research period.

\section{Conclusions}

Cell-free supernatant produced by the four isolates of LAB exhibited antimicrobial activity against a wide range of Gram-positive and Gram-negative foodborne bacteria, suggesting its potential research and application as a natural food antimicrobial agent. This antibacterial and antifungal LAB can be used in the food industry instead of chemical preservatives to produce organic foods. Furthermore, the excellent properties of LAB may preserve the nutritional value of foods and delay spoilage. From a health perspective, the conventional antimicrobial agents usually provide effective antibiotic therapy for bacterial infections but today many of the antimicrobial agents fail to respond to treatment and resulting in prolonged illness and greater risk of death. So using antimicrobial compounds from LAB may inhibit bacteria than the presently used antibiotics that mean it may have clinical value in treating certain microbial infection.

\section{Abbreviations}

AFB1: Aflatoxin B1

ANOVA: Analysis of variance

CFS: Cell-free supernatants

DDA: DzapexDox agar

ELISA: Enzyme-linked immunosorbent assay

EPSs: Exopolysaccharides

GRAS: Generally recognized as safe

LAB: $\quad$ Lactic acid bacteria

MDR: Multidrug resistance

MHA: Muller-Hinton agar

MRS: De Man, Rogosa, and Sharpe

$\mathrm{NaOH}$ : Sodium hydroxide

OD: Optical density

SOP: $\quad$ Standard operating procedure

SPSS: $\quad$ Statistical Package for Social Sciences

YESB: $\quad$ Yeast extract sucrose broth.

\section{Data Availability}

The datasets generated and/or analyzed during the current study are not publicly available due to ethical and confidentiality reasons but are available from the corresponding author upon reasonable request under the ethics committee's approval.

\section{Additional Points}

The standard strains used for this experimental study were Staphylococcus aureus ATCC25923, Klebsiella pneumonia ATCC700603, Pseudomonas aeruginosa ATCC27853, Escherichia coli ATCC25922, and Aspergillus flavus. The strains were obtained from the collection center of Ethiopian Public Health Institute (EPHI) except Aspergillus flavus which was isolated and identified following growth on selective DzapexDox Agar (DDA) followed by morphological and microscopic characteristics. These strains used for experimental study were destroyed after the study was completed by autoclaving at a temperature of $121^{\circ} \mathrm{C}$ for 15 minutes using saturated steam under 15 psi pressure.

\section{Ethical Approval}

Ethical clearance was obtained from the Ethical Committee of AMU, College of Medicine and Health Sciences, and permission was obtained from different local households 
and fermented beverage (Borde) making microenterprises and fishermen in Arba Minch, Ethiopia. The purpose of the study was clearly described to the fermented beverage (Borde) making microenterprises and fishermen including the benefit.

\section{Disclosure}

The funding agencies had no involvement in the design of the study, data collection and analysis, interpretation of data, and writing the manuscript.

\section{Conflicts of Interest}

The authors declare that they have no conflicts of interest.

\section{Authors' Contributions}

Belayneh Regasa Dadi, Fitsum Dejene, and Dagimawie Tadesse carried out proposal development, data collection, and data analysis and drafted the paper. All authors read and approved the final version of the paper.

\section{Acknowledgments}

The authors would like to thank those who were involved in this research.

\section{References}

[1] B. J. McCabe-Sellers and S. E. Beattie, "Food safety: emerging trends in foodborne illness surveillance and prevention," Journal of the American Dietetic Association, vol. 104, no. 11, pp. 1708-1717, 2004.

[2] J. C. Buzby, T. Roberts, C.-T. J. Lin, and J. M. MacDonald, Bacterial Foodborne Disease: Medical Costs and Productivity Losses, United States Department of Agriculture ERS, Washington, DC, USA, 1996.

[3] FDA, Most Common Foodborne Illnesses, https://www.fda. gov/files/food/published/Most-Common-FoodborneIllnesses-\%28PDF\%29.pdf, Food and Drug Administration, Silver Spring, MD, USA, 2021, https://www.fda.gov/files/ food/published/Most-Common-Foodborne-Illnesses-\% 28PDF\%29.pdf.

[4] CDC, Foodborne Germs and Illnesses, Center for Disease Control and Prevention, Atlanta, GA, USA, 2021, https:// www.cdc.gov/foodsafety/foodborne-germs.html.

[5] R. M. Elsanhoty, "Screening of some lactobacillus strains for their antifungal activities against aflatoxin-producing aspergilli in vitro and maize," Journal of Food, Agriculture \& Environment, vol. 6, no. 3-4, pp. 35-40, 2008.

[6] WHO, Aflatoxins. Food Safety Digest, World Health Organization, Geneva, Switzerland, 2018, https://www.who.int/ foodsafety/FSDigest_Aflatoxins_EN.pdf.

[7] P. Kumar, D. K. Mahato, M. Kamle, T. K. Mohanta, and S. G. Kang, "Aflatoxins: a global concern for food safety, human health and their management," Frontiers in Microbiology, vol. 7, p. 2170, 2017.

[8] V. Navale, K. R. Vamkudoth, S. Ajmera, and V. Dhuri, "Aspergillus derived mycotoxins in food and the environment: prevalence, detection, and toxicity," Toxicology Reports, vol. 8, pp. 1008-1030, 2021.
[9] S. Ananou, M. Maqueda, M. Martínez-Bueno, and E. Valdivia, "Biopreservation, an ecological approach to improve the safety and shelf-life of foods," Communicating Current Research and Educational Topics and Trends in Applied Microbiology, vol. 1, pp. 475-487, 2007.

[10] P.-T. Nguyen, T.-T. Nguyen, D.-C. Bui, P.-T. Hong, Q.-K. Hoang, and H.-T. Nguyen, "Exopolysaccharide production by lactic acid bacteria: the manipulation of environmental stresses for industrial applications," AIMS Microbiology, vol. 6, no. 4, pp. 451-469, 2020.

[11] S. Patel, A. Majumder, and A. Goyal, "Potentials of exopolysaccharides from lactic acid bacteria," Indian Journal of Microbiology, vol. 52, no. 1, pp. 3-12, 2012.

[12] A. K. Abdalla, M. M. Ayyash, A. N. Olaimat et al., "Exopolysaccharides as antimicrobial agents: mechanism and spectrum of activity," Frontiers in Microbiology, vol. 12, Article ID 664395, 2021.

[13] C. Zhang, M. Derrien, F. Levenez et al., "Ecological robustness of the gut microbiota in response to ingestion of transient food-borne microbes," The ISME Journal, vol. 10, no. 9, pp. 2235-2245, 2016.

[14] E. Pessione and S. Cirrincione, "Bioactive molecules released in food by lactic acid bacteria: encrypted peptides and biogenic amines," Frontiers in Microbiology, vol. 7, p. 876, 2016.

[15] L. G. Ruiz Rodríguez, V. M. Zamora Gasga, M. Pescuma, C. Van Nieuwenhove, F. Mozzi, and J. A. Sánchez Burgos, "Fruits and fruit by-products as sources of bioactive compounds. Benefits and trends of lactic acid fermentation in the development of novel fruit-based functional beverages," Food Research International, vol. 140, Article ID 109854, 2021.

[16] P. Calo-Mata, S. Arlindo, K. Boehme, T. de Miguel, A. Pascoal, and J. Barros-Velazquez, "Current applications and future trends of lactic acid bacteria and their bacteriocins for the biopreservation of aquatic food products," Food and Bioprocess Technology, vol. 1, no. 1, pp. 43-63, 2008.

[17] L. Settanni and A. Corsetti, "Application of bacteriocins in vegetable food biopreservation," International Journal of Food Microbiology, vol. 121, no. 2, pp. 123-138, 2008.

[18] M. Ashenafi and T. Mehari, "Some microbiological and nutritional properties of Borde and Shamita, traditional Ethiopian fermented beverages," The Ethiopian Journal of Health Development, vol. 9, pp. 105-110, 1995.

[19] G. Tadesse, E. Ephraim, and M. Ashenafi, "Assessment of the antimicrobial activity of lactic acid bacteria isolated from Borde and Shamita, traditional Ethiopian fermented beverages, on some foodborne pathogens and effect of growth medium on the inhibitory activity," Internet Journal of Food Safety, vol. 5, pp. 13-20, 2005.

[20] E. Ringo, S. Hossein, K. Ghosh, H. V. Doan, B. R. Beck, and S. Song, "Lactic acid bacteria in finfish-an update," Frontiers in Microbiology, vol. 9, p. 1818, 2018.

[21] A. G. Demissie, B. Chinthapalli, S. Tenaw, and D. V. Chitra, "Cultivation of micro-algae for production of biodiesel: an optimized process," Research in Biotechnology, vol. 7, 2016.

[22] A. Kumar and D. Kumar, "Characterization of Lactobacillus isolated from dairy samples for probiotic properties," $A n$ aerobe, vol. 33, pp. 117-123, 2015.

[23] M. P. Arena, A. Silvain, G. Normanno et al., "Use of Lactobacillus plantarum strains as a bio-control strategy against food-borne pathogenic microorganisms," Frontiers in $\mathrm{Mi}$ crobiology, vol. 7, p. 464, 2016.

[24] M. Kojic, J. Svircevic, A. Banina, and L. Topisirovic, "Bacteriocin-Producing Strain of Lactococcus lactis subsp. 
diacitilactis S50," Applied and Environmental Microbiology, vol. 57, no. 6, pp. 1835-1837, 1991.

[25] B. S. L. Jenie, B. P. Priosoeryanto, R. Syarief, and Rekso, "Mode of action Temukunci (Kaempferiapandurata) essential oil on E. coli K1. 1 cell determined by leakage of material cell and salt tolerance assays," HAYATI Journal of Biosciences, vol. 15, no. 2, pp. 56-60, 2008.

[26] N. H. Gomah, W. Ragab, and L. Bullerman, "Inhibition of fungal growth and aflatoxin B1 production by some Lactobacillus strains," Assiut Journal of Agricultural Sciences, vol. 40, pp. 27-36, 2009.

[27] N. Azeem, M. Nawaz, A. A. Anjum et al., "Activity and anti-aflatoxigenic effect of indigenously characterized probiotic lactobacilli against Aspergillus flavus-a common poultry feed contaminant," Animals, vol. 9, no. 4, p. 166, 2019.

[28] R. Darsanaki, M. Rokhi, Morteza, A. Aliabadi, and K. Issazadeh, "Antimicrobial activities of lactobacillus strains isolated from fresh vegetables," Middle-East Journal of Scientific Research, vol. 11, pp. 1216-1219, 2012.

[29] M. Pehrson, I. Mancilha, and C. Pereira, "Antimicrobial activity of probiotic Lactobacillus strains towards gramnegative enteropathogens," European International Journal of Science and Technology, vol. 4, pp. 136-149, 2015.

[30] S. Ogunbanwo, A. Sanni, and A. Onilude, "Characterization of bacteriocin produced by Lactobacillus plantarum F1 and Lactobacillus brevis OG1," African Journal of Biotechnology, vol. 2, no. 8, pp. 219-227, 2003.

[31] L. A. M. Ryan, E. Zannini, F. Dal Bello, A. Pawlowska, P. Koehler, and E. K. Arendt, "Lactobacillus amylovorus DSM 19280 as a novel food-grade antifungal agent for bakery products," International Journal of Food Microbiology, vol. 146 , no. 3, pp. 276-283, 2011.

[32] P. Sanlibaba and Y. Güçer, "Antimicrobial activity of lactic acid bacteria," Journal of International Scientific Publications, vol. 3, pp. 451-457, 2015.

[33] D. Ren, J. Zhu, S. Gong, H. Liu, and H. Yu, “Antimicrobial characteristics of lactic acid bacteria isolated from homemade fermented foods," BioMed Research International, vol. 2018, Article ID 5416725, 9 pages, 2018.

[34] P. Rattanachaikunsopon and P. Phumkhachorn, "Lactic acid bacteria: their antimicrobial compounds and their uses in food production," Annals of Biological Research, vol. 1, no. 4, pp. 218-228, 2010.

[35] L. Stoyanova, E. Ustiugova, and A. Netrusov, "Antibacterial metabolites of lactic acid bacteria: their diversity and properties," Prikladnaia biokhimiia i mikrobiologiia, vol. 48, pp. 259-275, 2012.

[36] Z. N. François, K. P. Marie, T. A. H. Noëlle, and G. W. R. Emeric, "Antimicrobial activity of a bacteriocin produced by Lactobacillus plantarum $29 \mathrm{~V}$ and strain's viability in palm kernel oil," International Journal of Nutrition and Food Sciences, vol. 2, no. 3, pp. 102-108, 2013.

[37] M. L. Scatassa, R. Gaglio, C. Cardamone et al., "Anti-listeria activity of lactic acid bacteria in two traditional Sicilian cheeses," Italian Journal of Food Safety, vol. 6, no. 1, p. 6191, 2017.

[38] J. Nowroozi, M. Mirzaii, and M. Norouzi, "Study of lactobacillus as probiotic bacteria," Iranian Journal of Public Health, vol. 33, no. 2, pp. 1-7, 2004.

[39] V. K. Bajpai, J. H. Han, I. A. Rather et al., "Characterization and antibacterial potential of lactic acid bacterium Pediococcus pentosaceus 4I1 isolated from freshwater fish Zacco koreanus," Frontiers in Microbiology, vol. 7, 2016.
[40] G. Liu, G. Ren, L. Zhao, L. Cheng, C. Wang, and B. Sun, "Antibacterial activity and mechanism of bifidocin A against Listeria monocytogenes," Food Control, vol. 73, 2016.

[41] C. De Muynck, A. I. J. Leroy, S. De Maeseneire, F. Arnaut, W. Soetaert, and E. J. Vandamme, "Potential of selected lactic acid bacteria to produce food compatible antifungal metabolites," Microbiological Research, vol. 159, no. 4, pp. 339-346, 2004.

[42] V. Aiko and A. Mehta, "Occurrence, detection and detoxification of mycotoxins," Journal of biosciences, vol. 40, no. 5 , pp. 943-954, 2015. 